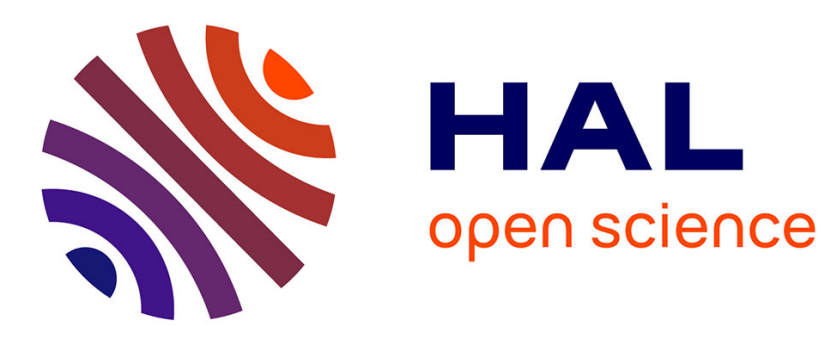

\title{
Wireless Electromechanical Readout of Chemical Information
}

\author{
Lin Zhang, Bhavana Gupta, Bertrand Goudeau, Nicolas Mano, Alexander
}

Kuhn

\section{- To cite this version:}

Lin Zhang, Bhavana Gupta, Bertrand Goudeau, Nicolas Mano, Alexander Kuhn. Wireless Electromechanical Readout of Chemical Information. Journal of the American Chemical Society, 2018, 140 (45), pp.15501-15506. 10.1021/jacs.8b10072 . hal-02101547

\section{HAL Id: hal-02101547 \\ https://hal.science/hal-02101547}

Submitted on 16 Apr 2019

HAL is a multi-disciplinary open access archive for the deposit and dissemination of scientific research documents, whether they are published or not. The documents may come from teaching and research institutions in France or abroad, or from public or private research centers.
L'archive ouverte pluridisciplinaire HAL, est destinée au dépôt et à la diffusion de documents scientifiques de niveau recherche, publiés ou non, émanant des établissements d'enseignement et de recherche français ou étrangers, des laboratoires publics ou privés. 


\title{
Wireless electromechanical readout of chemical information
}

\author{
Lin Zhang ${ }^{1,2 \#}$, Bhavana Gupta ${ }^{1 \#}$, Bertrand Goudeau ${ }^{1}$, Nicolas Mano ${ }^{2}$, Alexander Kuhn ${ }^{1 *}$ \\ ${ }^{1}$ Univ. Bordeaux, CNRS UMR 5255, Bordeaux INP, ENSCBP, 16 avenue Pey Berland, 33607 Pessac, France \\ ${ }^{2}$ Centre de Recherche Paul Pascal, CNRS UMR 5031, Avenue Albert Schweitzer, 33600 Pessac, France
}

\begin{abstract}
Collecting electrochemical information concerning the presence of molecules in a solution is usually achieved by measuring current, potential, resistance or impedance via connection to a power supply. Here, we suggest wireless electromechanical actuation as a straight-forward readout of chemical information. This can be achieved based on the concept of bipolar electrochemistry, which allows measuring the presence of different model species in a quantitative way. We validate the concept by using a free-standing polypyrrole film. Its positively polarized extremity participates in an oxidation of the analyte and delivers electrons to the opposite extremity for the reduction of the polymer. This reduction is accompanied by the insertion of counter ions and thus leads to partial swelling of the film, inducing its bending. The resulting actuation is found to be a linear function of the analyte concentration and also a Michaelis-Menten type correlation is obtained for biochemical analytes. This electromechanical transduction allows an easy optical readout and opens up very interesting perspectives not only in the field of sensing, but also far beyond, such as for the elaboration of self-regulating biomimetic systems.
\end{abstract}

\section{INTRODUCTION}

Conducting polymers are popular candidates to be used as smart materials for the transduction of chemical information, light emission, energy storage, photovoltaics and actuation due to their easy synthesis and interesting electrochemical properties. $^{1-5}$ Most importantly, their $\pi$-conjugated system allows charge transport as well as fast and reversible redox activity, and therefore makes them suitable as amperometric, potentiometric, conductometric and impedometric transducers. ${ }^{4,6-8}$ In all these cases the polymer needs to be connected to a power supply or an electric measuring device. Therefore, it is of great interest to explore alternative approaches using a wireless concept. As an example, conductometric wireless polyaniline sensors have been developed recently based on near field communication (NFC) technology. ${ }^{9}$ Typical features of conducting polymers such as color and volume change can equally be used as ingredients to develop sensors or biosensors. ${ }^{9-11}$ In this context bipolar electrochemistry (BPE) is an interesting alternative to trigger in a wireless way a change of the above mentioned physical properties of the conducting polymer. ${ }^{12,13}$ BPE is a straight-forward way to break the symmetry of chemical systems and has been used in the past for many applications in various fields ranging from materials science to catalysis and analysis. ${ }^{14-16}$ It has been employed, among others, to modify conducting or semiconducting objects, ${ }^{16-22}$ allowing an easy access to Janus particles ${ }^{18,20}$, to trigger electrochromism, photoluminescence and electroluminescence in conducting polymers $^{12,13,23-25}$ and to generate directional motion or forced propulsion of particles. ${ }^{21,22}$

We recently reported the use of BPE also for the wireless actuation of polypyrrole (PPy) based on an asymmetric volume change. ${ }^{26}$ An electric field, generated in the electrolyte, breaks the symmetry of the PPy film due to its polarization with respect to the solution. This polarization results in spatially separated oxidation and reduction reactions, located at the two ends of the polymer object. Together with an additional intrinsic asymmetry, related to the different morphologies of the two faces of the film, this allows a directional bending and motion of the PPy film. ${ }^{26,27}$

We demonstrate here with several proof-of-principle experiments that this wireless mechanical deformation of a freestanding polymer layer can be directly correlated in a quantitative way with the concentration of different model molecules such as hydrogen peroxide, hydroquinone and glucose. BPE has been already proposed as an attractive approach to collect information about the chemical composition of a solution. Seminal work by the Crooks group demonstrated that the presence of an analyte can be coupled to either the dissolution of a metal ${ }^{28-30}$ or the generation of electrochemiluminescence (ECL). ${ }^{31}$ The latter concept could also be generalized to ECL emission in the bulk ${ }^{32,33}$ or from moving particles. ${ }^{34}$ Various other interesting approaches have highlighted the outstanding features and advantages of BPE in the context of transduction of chemical information. ${ }^{35-43}$ However, the possibility of an electromechanical bipolar readout has not been explored so far. The principal of this concept relies again on the decoupling of the sensing chemistry from the reporting functions (Scheme 1). The bipolar object, a sheet of the conducting polymer, is placed between two graphite feeder electrodes. ${ }^{16,20}$ Upon application of a constant electric field, the PPy strip is polarized in an asymmetric way, the extremity with a polarization $\delta^{+}$acting as an anode, whereas the opposite extremity with a polarization $\delta$ behaving as a cathode. This break of symmetry triggers an oxidation and reduction reaction at the two terminal ends of the PPy, with the peculiarity that PPy can participate itself in the redox reactions. ${ }^{44}$ Oxidized PPy does not undergo further oxidation, thus only the extremity involved in the reduction reaction shows actuation behavior. Reduction of the PPy is accompanied by an intake of cations in order to ensure electroneutrality. This movement of ions is responsible for the swelling of the PPy film. However, as the two faces of the PPy strip have a different morphology and surface roughness, their swelling behavior is not identical. The rough side (facing the electrolyte during preparation of the film by electropolymerization) allows a more efficient uptake 
of cations compared to the smooth side (facing the substrate during electropolymerization). Therefore, the bending occurs preferentially towards the smooth side and is perfectly reversible upon removal or inversion of the electric field. Since at the anodically polarized extremity the oxidation cannot involve PPy itself, the conversion of a redox active molecule from the electrolyte has to ensure charge equilibration. This enabled us to propose the development of a new analytical readout mechanism described in this contribution.

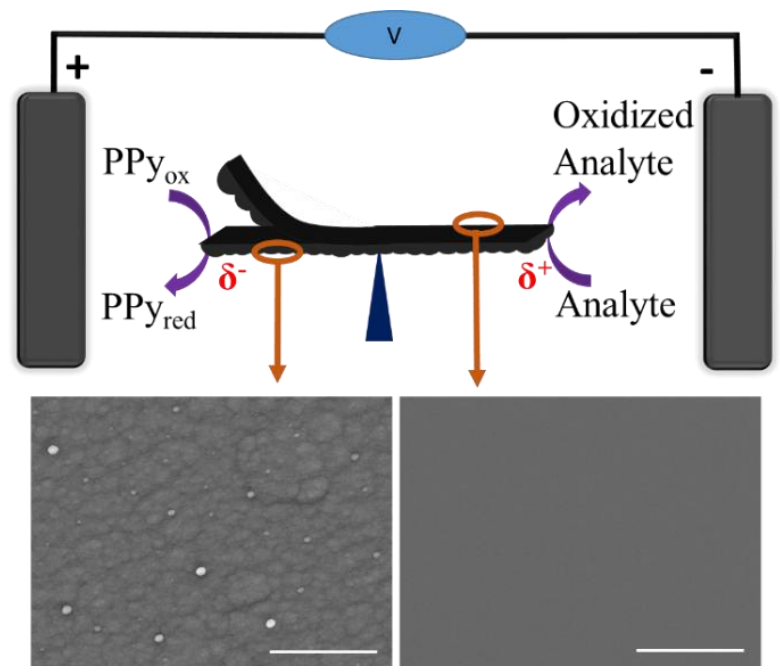

Scheme 1: Schematic illustration of the bipolar electrochemical cell used for electromechanical readout. The free-standing polypyrrole (PPy) film is placed between two feeder electrodes. $\delta^{+}$and $\delta^{-}$indicate the polarization potential at the two extremities. Scanning electron microscopic images of the two faces of the PPy film are shown below. Scale bars: $30 \mu \mathrm{m}$.

\section{RESULTS AND DISCUSSION}

If the experiment depicted in Scheme 1 is carried out in an aqueous medium, water is the most abundant molecule which can be oxidized in order to provide the electrons needed for PPy reduction at the opposite end. The simultaneous, spatially separated, PPy reduction and water oxidation requires a threshold electric field which needs to be applied by the feeder electrodes. For the present set-up the critical experimental value is $1.8 \mathrm{~V} / \mathrm{cm}$. This is higher than the value calculated from the cyclic voltammogram in Figure S1 A $(0.7 \mathrm{~V} / \mathrm{cm})$, among others due to overpotentials at the feeder electrodes and the bipolar electrode. If the electrolyte contains redox species which can be oxidized more easily than water, actuation will occur already at a lower electric field. Moreover, for an electric field with a given amplitude, actuation increases with increasing concentration of analyte. Therefore, an electric field which is slightly below the threshold value necessary for water oxidation is imposed on the bipolar electrode $(<1.8 \mathrm{~V} / \mathrm{cm})$. In this case no bending is observed. Only after addition of the more reactive chemical species bending starts to occur and varies as a function of time. In a first set of proof-of-principle experiments we tested hydrogen peroxide and hydroquinone as target molecules to validate the general concept.

Hydrogen peroxide is known for its catalytic and electrocatalytic oxidation on metal surfaces which is easier to achieve than water oxidation. ${ }^{45,46}$ However, since $\mathrm{H}_{2} \mathrm{O}_{2}$ can also be reduced at relatively low overpotentials, it is necessary to evaluate the possible competition between the reduction of PPy and $\mathrm{H}_{2} \mathrm{O}_{2}$, which might interfere with the bending mechanism. Cyclic voltammograms of PPy with and without $\mathrm{H}_{2} \mathrm{O}_{2}$ have been recorded (Figure S1 A). In the presence of $75 \mathrm{mM}$ $\mathrm{H}_{2} \mathrm{O}_{2}$, higher currents are observed for potentials more positive than $+0.4 \mathrm{~V}$ compared to the experiment in the absence of $\mathrm{H}_{2} \mathrm{O}_{2}$. This is due to the electrooxidation of $\mathrm{H}_{2} \mathrm{O}_{2}$ which occurs before water oxidation. On the other hand, the reduction current is also increased, however without a significant potential shift with respect to the reduction of PPy. Thus, the charge generated during $\mathrm{H}_{2} \mathrm{O}_{2}$ oxidation at the positively polarized extremity can be at least partially used for PPy reduction. The favored $\mathrm{H}_{2} \mathrm{O}_{2}$ oxidation will help in decreasing the threshold electric field value for bipolar actuation and the bending will depend on $\mathrm{H}_{2} \mathrm{O}_{2}$ concentration. To prove this assumption, we performed $\mathrm{BPE}$ with different $\mathrm{H}_{2} \mathrm{O}_{2}$ concentrations (Figure 1). The minimum concentration required to achieve a significant bending at $1.6 \mathrm{~V} / \mathrm{cm}$ is $10 \mathrm{mM}$. In the absence of $\mathrm{H}_{2} \mathrm{O}_{2}$ the same amplitude of bending can only be obtained when we apply a field of $1.8 \mathrm{~V} / \mathrm{cm}$ between the two feeder electrodes. In this case a current of $30 \mu \mathrm{A}$ is passing through the PPy film, which is enough to deliver a sufficient amount of charge at the time scale of minutes to obtain visible bending. When further increasing the $\mathrm{H}_{2} \mathrm{O}_{2}$ concentration, the degree of bending at a readout time of $60 \mathrm{~s}$ increases linearly up to $75 \mathrm{mM}$ (Figure 1C).

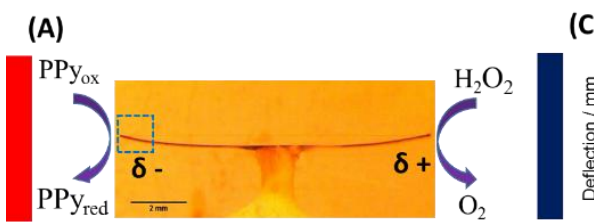

(B)
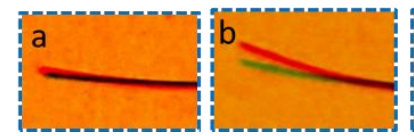

(C)

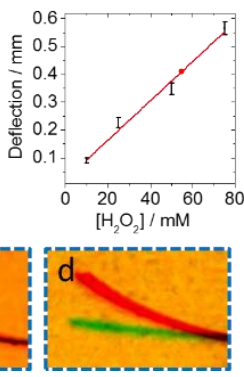

Figure 1: (A) Bipolar electromechanical set-up to measure $\mathrm{H}_{2} \mathrm{O}_{2}$ concentration in $0.1 \mathrm{M}$ PBS buffer. Blue and red borders denote the negative and positive feeder electrodes, respectively. (B) Zoom at the negatively polarized PPy extremity in the presence of (a) 10, (b) 25, (c) 50 and (d) $75 \mathrm{mM} \mathrm{H}_{2} \mathrm{O}_{2}$. The green colored PPy strip indicates its initial position and red the position after $60 \mathrm{sec}$. (C) Calibration curve for different $\mathrm{H}_{2} \mathrm{O}_{2}$ concentrations. The electric field between the feeder electrodes is $1.6 \mathrm{~V} / \mathrm{cm}$ for all measurements.

From these results it is clear that a redox active analyte which is easier to oxidize than $\mathrm{H}_{2} \mathrm{O}_{2}$ should be able to decrease even more the threshold potential for actuation. To confirm this idea, hydroquinone has been selected. Similar to $\mathrm{H}_{2} \mathrm{O}_{2}$, the oxidation of hydroquinone is first examined by cyclic voltammetry (Figure S1 B). In the presence of $20 \mathrm{mM}$ hydroquinone, the current starts increasing for potentials more positive than $0.0 \mathrm{~V}$. This indicates that the electrochemical oxidation of hydroquinone is much easier than water or $\mathrm{H}_{2} \mathrm{O}_{2}$ oxidation. On the other hand, the reduction of benzoquinone and PPy occur in a similar potential range. The expected threshold of electric field for triggering the actuation in the presence of hydroquinone can be again calculated by cyclic voltammetry (Figure $\mathrm{S} 1 \mathrm{~B}$ ) and a value of $0.2 \mathrm{~V} / \mathrm{cm}$ is obtained. However, in the bipolar set-up a higher minimum field of $1.2 \mathrm{~V} / \mathrm{cm}$ is neces- 
sary for the same reasons as mentioned above. In order to be able to make a comparison between $\mathrm{H}_{2} \mathrm{O}_{2}$ and hydroquinone in terms bending efficiency, we've chosen also $1.6 \mathrm{~V} / \mathrm{cm}$ for the bipolar actuation in the presence of hydroquinone. The fact that hydroquinone oxidation is much easier results in a more pronounced deformation of PPy. A linear dependence of the bending on concentration is obtained from 5 to $20 \mathrm{mM}$ $\left(\mathrm{R}^{2}=0.998\right)$ (Figure S2).

Since $\mathrm{H}_{2} \mathrm{O}_{2}$ is the product of many enzymatic reactions and quinones are popular mediators in bioelectrochemical systems $^{47}$ the presented approach might also be useful for biosensing. In such a case, the electromechanical readout would be based on a polymer strip modified with the corresponding enzyme. To validate this idea from a fundamental point of view, glucose has been chosen as a target molecule. As for $\mathrm{H}_{2} \mathrm{O}_{2}$, the intention here is not to propose a new glucose sensor, but to provide a general demonstration that a coupling between an enzymatic reaction and a mechanical deformation is possible. This allows envisioning self-regulating biomimetic systems, based on electrochemical feed-back mechanisms, such as stimuli-responsive valves or intelligent drug-delivery systems. Classical electroenzymatic glucose sensing has been well developed in the past decades. ${ }^{48-50}$ For glucose oxidase (GOx), which can oxidize glucose to gluconolactone, a mediator is needed to shuttle electrons between the $\mathrm{FAD} / \mathrm{FADH}_{2}$ redox center of GOx and the electrode surface. In this work, we immobilized the organic charge transfer complex (CTC) tetrathiafulvalene-tetracyanoquinodimethane (TTF-TCNQ) as a mediator along with glucose oxidase on the rough face of the PPy strip. ${ }^{48,51}$ TTF-TCNQ is well known for its redox activity around $+0.1 \mathrm{~V} .^{52}$ To avoid leaching of the enzymes from the PPy surface, a gelatin layer is casted on top. Following a strategy analogous to what has been reported in the literature, ${ }^{53}$ it is possible to enhance the current originating from glucose oxidation by increasing the width of the positively polarized enzyme modified extremity (Figure 2A). The 8 times bigger surface area of this anodic extremity thus allows a higher loading with GOx and CTC, which therefore can provide comparatively more charges for the reduction of PPy and improve the actuation amplitude. The GOx-CTC modified side is fixed on a larger support in order to avoid bending purely due to the higher mass of conducting polymer, enzyme, mediator and protection layer.

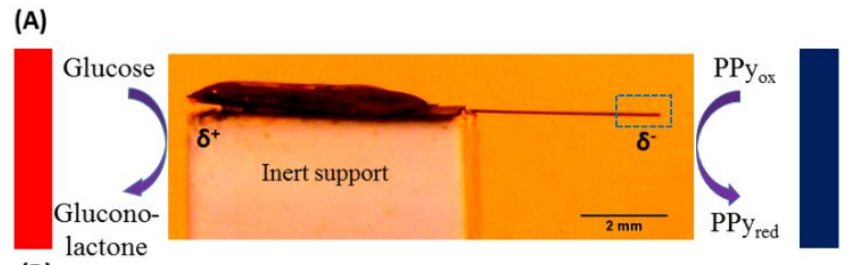

(B)

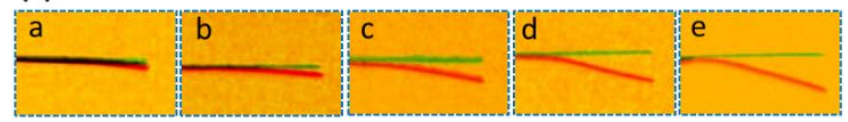

Figure 2: (A) Bipolar electromechanical readout to estimate glucose concentration in $0.1 \mathrm{M}$ PBS buffer using a CTCGOx/gel modified PPy strip. Blue and red borders denote the negative and positive feeder electrodes, respectively. (B) Zoom of the negatively polarized PPy extremity in the presence of (a) 5, (b) 10, (c) 20, (d), 30 and (e) $50 \mathrm{mM}$ glucose. Green color of the PPy strip represents its initial position and red the position after $60 \mathrm{sec}$. The electric field between the feeder electrodes is $1.3 \mathrm{~V} / \mathrm{cm}$.
An electric field of $1.3 \mathrm{~V} / \mathrm{cm}$ is used in this case to make sure that bending can only occur when the enzymatic reaction is involved. The deflection resulting from electroactuation of the negatively polarized side increases with increasing glucose concentration at a readout time of 1 min as shown in Figure 2 B. Relative errors have been calculated by measuring the deflection three times and are on average around 5\% with an associated detection limit of $5 \mathrm{mM}$. As the intention of this work is not to develop a new type of glucose sensor, the performance of the device has not been optimized, however the range of measurable concentrations is nevertheless compatible with classic values in blood $(5-10 \mathrm{mM})$. Electroenzymatic catalysis obviously continues after $1 \mathrm{~min}$, but the direction of deflection starts to reverse. We monitored this peculiar long term evolution of the bending in the presence of $50 \mathrm{mM}$ glucose (see detailed explanation in SI, Figure S3 and Video 1). The maximum deflection at $60 \mathrm{sec}$ has been chosen to analyze quantitatively the actuation as a function of glucose concentration (Figure $3 \mathrm{~A}$ ). It needs to be mentioned that if the oxidation potential of the analyte is close to the one of PPy, a slow degradation of PPy might occur due to its partial overoxidation. In the present GOx-CTC system, since the oxidation potential of CTC $(\sim 0.05 \mathrm{~V})$ is much lower than that of PPy $(\sim 0.4 \mathrm{~V})$, no obvious degradation of PPy was observed. At room temperature, the deflection experiment can be again carried out again with a comparable performance even after $6 \mathrm{~h}$.

In parallel, the classic electrocatalytic response of a GOxCTC modified PPy film was also evaluated by cyclic voltammetry (Figure 3B). For both calibration curves we observe a typical Michaelis-Menten type behavior. The apparent $\mathrm{K}_{\mathrm{M}}$ for glucose was estimated to be $33 \pm 2 \mathrm{mM}$ with the classic electrochemical readout, compared to $53 \pm 3 \mathrm{mM}$ for the bipolar electromechanical readout. Taking into account the completely different measurement concepts, these values are quite comparable and in good agreement with the literature, indicating a $\mathrm{K}_{\mathrm{M}}$ of $33-110 \mathrm{mM}^{54,55}$
(A)

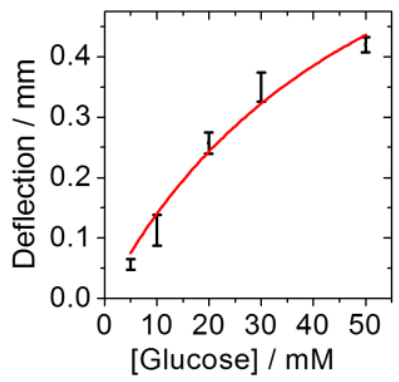

(B)

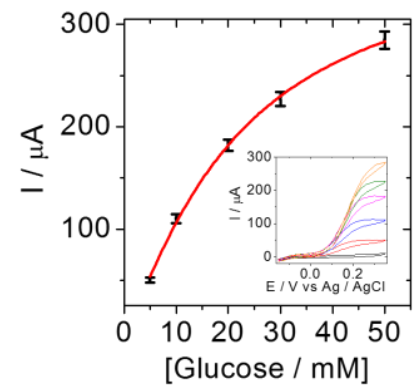

Figure 3: Calibration curves for (A) bipolar electromechanical readout at $\mathrm{t}=1 \mathrm{~min}$ and $(\mathrm{B})$ conventional electrochemical measurement at +0.35 vs $\mathrm{Ag} / \mathrm{AgCl}$ using a CTC-GOx/gel modified PPy strip as a biosensor. Inset: cyclic voltammograms of PPy/CTC-GOx/gel in the presence of different concentrations of glucose in PBS at a scan rate of $10 \mathrm{mV} / \mathrm{s}$.

\section{CONCLUSION}

We demonstrate the possibility to achieve a quantitative wireless electromechanical readout of the presence of several chemical species in aqueous solution using free-standing PPy films in a bipolar electrochemical cell. In the case of an initially oxidized PPy strip, its anodically polarized side acts as a 
center for chemical conversion and the cathodic side for the signal transduction in the form of actuation. Modulating the relative size of the anodic extremity with respect to the cathodic one allows controlling the amplitude of the readout. In a set of proof-of-principal experiments we were able to validate this concept of bipolar sensing for different molecules, including electroenzymatic conversion schemes. The main advantages of the approach are related to the intrinsic features of bipolar electrochemistry, namely a wireless transduction, the possibility of massive parallel screening and low cost. The readout concept might also be extended to the reductive detection of molecules under the condition to employ at least partially reduced PPy. In that case the optical detection should take place at the anodically polarized side due to the oxidation and subsequent bending of the polymer.

The presented straight-forward approach can be generalized to a large variety of chemical or biological analytes, as long as they are easier to oxidize than water. Slightly adapting the device should also enable for example immunosensing, DNA analysis or enantioselective detection. This makes it a promising tool for various applications, not only in the field of sensing, but even for more sophisticated concepts, such as biomimetic electrochemical feed-back systems, allowing the design of stimuli responsive valves, intelligent drug delivery schemes or Boolean logic gates.

\section{EXPERIMENTAL SECTION}

Electrochemical synthesis of polypyrrole film. For the synthesis of the polypyrrole film, $25 \mathrm{~mL}$ of pyrrole $(0.2 \mathrm{M})$ (Sigma Aldrich) are dissolved in Milli Q water along with $0.25 \mathrm{M}$ dodecyl benzene sulfonate (Sigma Aldrich). After complete dissolution of both components, two gold coated glass plates $(3 \mathrm{~cm} \times 1.5 \mathrm{~cm})$ are fixed in parallel in the beaker. $\mathrm{Ag} / \mathrm{AgCl}$ was used as a reference electrode. A fixed current of $7.75 \mathrm{~mA}$ is applied for 5200s for the polymerization of pyrrole. After completion of the polymerization, the polypyrrole coated gold surface is washed with distilled water. The polymer is then peeled off from the surface with the help of a sharp knife. The wet polymer film is kept between two glass slides overnight for further use. The polypyrrole surface is characterized using scanning electron microscopy (Hitachi, TM-1000) after Au sputtering the polymer surface to reduce electric charging.

Synthesis of tetrathiafulvalenetetracyanoquinodimethane charge transfer crystals (TTFTCNO CTC). For the synthesis of TTF-TCNQ CTC, TTF $(0.1 \mathrm{M})$ and TCNQ $(0.1 \mathrm{M})$ is dissolved in $10 \mathrm{ml}$ acetonitrile in two separate beakers. After complete dissolution, the TTF solution is added to the TCNQ solution under stirring. Black CTC are formed immediately. After 30 minutes of mixing, CTC are washed with acetonitrile followed by diethyl ether. Finally, the resulting CTC are dried in a hood at room temperature for $12 \mathrm{~h}$. After drying the CTC are collected in a closed vial and used for immobilization.

Fabrication of glucose oxidase (GOx) modified polypyrrole. A polypyrrole strip with a size of $1.0 \mathrm{~cm} \times 0.4$ $\mathrm{cm}$ is cut. $6 \mathrm{mg}$ TTF-TCNQ crystals are grinded in a pastel mortar, then mixed with 6mg of GOx (from Aspergillus niger, Sigma Aldrich) predissolved in $100 \mu \mathrm{l} 0.1 \mathrm{M}$ phosphate buffer $(\mathrm{pH}$ 7.0). $10 \mu \mathrm{l}$ of the mixture are drop casted onto the rough face of one half of the polypyrrole strip (roughly $0.5 \mathrm{~cm} \times 0.4$ $\mathrm{cm})$. After complete drying, $2 \mu \mathrm{l}$ of a preheated gelatin solution $(12.5 \mathrm{mg}$ in $250 \mu \mathrm{l})$ is casted on top of the enzyme layer. After drying, the width of the unmodified part of the polypyrrole strip is reduced to $0.05 \mathrm{~cm}$. Such a GOx-CTC modified polypyrrole strip is used for glucose sensing in $0.1 \mathrm{M}$ PBS (pH 7.0) by bipolar electrochemistry.

Bipolar electromechanical readout. For bipolar electromechanical readout of hydrogen peroxide and quinone, a pristine polypyrrole strip with a size of $10 \mathrm{~mm} \mathrm{x} 1 \mathrm{~mm}$ is positioned at the center axis of the bipolar cell. For the electroenzymatic analysis of glucose, the GOx-CTC modified polypyrrole part is fixed at the top of a holder in the bipolar cell. Two graphite feeder electrodes are placed $5 \mathrm{~cm}$ apart on the right and left side of the polypyrrole strip. In all bipolar experiments, 0.1 M PBS ( $\mathrm{pH}$ 7.0) is used as electrolyte to provide a sufficient amount of ions during the process of bipolar electrochemistry. Different concentrations of hydrogen peroxide, hydroquinone and glucose are added to the buffer solution in order to measure the degree of bending of the polypyrrole strip. Actuation was recorded using a macroscope (LEICA Z16 APO) in video mode.

\section{ASSOCIATED CONTENT}

\section{Supporting Information}

Cyclic voltammograms and deflection pictures of polypyrrole in the analyte medium. Video of polypyrrole actuation in the presence of analyte.

\section{AUTHOR INFORMATION}

\section{Corresponding Author}

kuhn@enscbp.fr

\section{Author Contributions}

\# L.Z. and B.G. contributed equally.

\section{Notes}

The authors declare no competing financial interests.

\section{ACKNOWLEDGMENTS}

This study has received financial support from the French State in the framework of the "Investments for the future" Program, IdEx Bordeaux, reference ANR-10-IDEX-03-02. It has also been funded by the ANR project BIO3 (ANR-16-CE19-0001-03). A.K. acknowledges financial support from the Institut Universitaire de France. The work has also received funding from the European Research Council (ERC) under the European Union's Horizon 2020 research and innovation program (grant agreement $\mathrm{n}^{\circ}$ 741251, ERC Advanced grant ELECTRA).

\section{REFERENCES}

(1) Aydemir, N.; Malmstrom, J.; Travas-Sejdic, J., Conducting polymer based electrochemical biosensors. J. Phys. Chem. Chem. Phys. 2016, 18, 8264-8277.

(2) Naseri, M.; Fotouhi, L.; Ehsani, A., Recent progress in the development of conducting polymer-based nanocomposites for electrochemical biosensors applications: A Mini-Review. Chem. Rec. 2018, 18, 599-618.

(3) Zhou, Q.; Shi, G., Conducting polymer-based catalysts. J. Am. Chem. Soc. 2016, 138, 2868-2876.

(4) Ibanez, J. G.; Rincón, M. E.; Gutierrez-Granados, S.; Chahma, M. h.; Jaramillo-Quintero, O. A.; Frontana-Uribe, B. A., Conducting poly- 
mers in the fields of energy, environmental remediation, and chemicalchiral sensors. Chem. Rev. 2018, 118, 4731-4816.

(5) Ishiguro, Y.; Inagi, S.; Fuchigami, T., Site-controlled application of electric potential on a conducting polymer "canvas". J. Am. Chem. Soc. 2012, 134, 4034-4036.

(6) Lindfors, T.; Aarnio, H.; Ivaska, A., Potassium-selective electrodes with stable and geometrically well-defined internal solid contact based on nanoparticles of polyaniline and plasticized poly(vinyl chloride). Anal. Chem. 2007, 79, 8571-8577.

(7) Vanamo, U.; Bobacka, J., Instrument-free control of the standard potential of potentiometric solid-contact ion-selective electrodes by shortcircuiting with a conventional reference electrode. Anal. Chem. 2014, 86, 10540-10545.

(8) Guziński, M.; Lisak, G.; Sokalski, T.; Bobacka, J.; Ivaska, A.; Bocheńska, M.; Lewenstam, A., Solid-contact ion-selective electrodes with highly selective thioamide derivatives of p-tert-Butylcalix[4]arene for the determination of lead(II) in environmental samples. Anal. Chem. 2013, $85,1555-1561$.

(9) Ma, Z.; Chen, P.; Cheng, W.; Yan, K.; Pan, L.; Shi, Y.; Yu, G., Highly sensitive, printable nanostructured conductive polymer wireless sensor for food spoilage detection. Nano Lett. 2018, 18, 4570-4575

(10) Martinez, J. G.; Otero, T. F., Biomimetic dual sensing-actuators: theoretical description. sensing electrolyte concentration and driving current. J. Phys. Chem. B 2012, 116, 9223-9230.

(11) Gicevičius, M.; Ramanavičienè, A.; Mikoliūnaitè, L.; Ramanavičius, A. In optical sensors based on electrochromic conducting polymers, 2017 IEEE 7th International Conference Nanomaterials: Application \& Properties (NAP), 10-15 Sept. 2017.

(12) Inagi, S.; Ishiguro, Y.; Atobe, M.; Fuchigami, T., Bipolar Patterning of Conducting Polymers by Electrochemical Doping and Reaction. Angew. Chem. Int. Ed. 2010, 49, 10136-10139.

(13) Inagi, S., Fabrication of gradient polymer surfaces using bipolar electrochemistry. Polym. J. 2016, 48, 39-44.

(14) Fosdick, S. E.; Knust, K. N.; Scida, K.; Crooks, R. M., Bipolar electrochemistry. Angew. Chem. Int. Ed. 2013, 52, 10438-10456.

(15) Koefoed, L.; Pedersen, S. U.; Daasbjerg, K., Bipolar electrochemistry-A wireless approach for electrode reactions. Curr. Opin. Electrochem. 2017, 2, 13-17.

(16) Loget, G.; Zigah, D.; Bouffier, L.; Sojic, N.; Kuhn, A., Bipolar electrochemistry: from materials science to motion and beyond. Acc. Chem. Res. 2013, 46, 2513-2523.

(17) Tiewcharoen, S.; Warakulwit, C.; Lapeyre, V.; Garrigue, P.; Fourier, L.; Elissalde, C.; Buffière, S.; Legros, P.; Gayot, M.; Limtrakul, J.; Kuhn, A., Anisotropic metal deposition on $\mathrm{TiO}_{2}$ particles by electric-fieldinduced charge separation. Angew. Chem. Int. Ed. 2017, 56, 11431-11435.

(18) Yadnum, S.; Roche, J.; Lebraud, E.; Négrier, P.; Garrigue, P.; Bradshaw, D.; Warakulwit, C.; Limtrakul, J.; Kuhn, A., Site-selective synthesis of janus-type metal-organic framework composites. Angew. Chem. Int. Ed. 2014, 53, 4001-4005.

(19) Loget, G.; Roche, J.; Kuhn, A., True bulk synthesis of janus objects by bipolar electrochemistry. Adv. Mater. 2012, 24, 5111-5116.

(20) Bouffier, L.; Zigah, D.; Sojic, N.; Kuhn, A. Recent advances in bipolar electrochemistry, In Electroanalytical Chemistry: A Series of Advances, Bard, A. J.; Zoski, C. G. Eds.; CRC Press: 2017; Vol. 27, p 27.

(21) Loget, G.; Kuhn, A., Propulsion of microobjects by dynamic bipolar self-regeneration. J. Am. Chem. Soc. 2010, 132, 15918-15919.

(22) Bouffier, L.; Ravaine, V.; Sojic, N.; Kuhn, A., Electric fields for generating unconventional motion of small objects. Curr. Opin. Colloid Interface Sci. 2016, 21, 57-64.

(23) Hu, S.; Chi, X.; Chen, S.; AlTal, F.; Gao, J., Visualizing the bipolar electrochemistry of electrochemically doped luminescent conjugated polymers. J. Phys. Chem. C 2017, 121, 8409-8415.

(24) $\mathrm{Hu}, \mathrm{S}$; Gao, J., Wireless electroluminescence: polymer lightemitting electrochemical cells with inkjet-printed 1D and 2D bipolar electrode arrays. J. Phys. Chem. C 2018, 122, 9054-9061.

(25) He, L.; Wang, X.; Duan, L., Enhancing the overall performances of blue light-emitting electrochemical cells by using an electroninjecting/transporting ionic additive. ACS Appl. Mater. Interfaces 2018, 10, 11801-11809.

(26) Gupta, B.; Goudeau, B.; Kuhn, A., Wireless electrochemical actuation of conducting polymers. Angew. Chem. Int. Ed. 2017, 56, 14183 14186.

(27) Gupta, B.; Goudeau, B.; Garrigue, P.; Kuhn, A., Bipolar conducting polymer crawlers based on triple symmetry breaking. Adv. Funct. Mater. 2018, 28, 1705825-1705830.
(28) Chow, K.-F.; Chang, B.-Y.; Zaccheo, B. A.; Mavré, F.; Crooks, R M., A sensing platform based on electrodissolution of a Ag bipolar electrode. J. Am. Chem. Soc. 2010, 132, 9228-9229.

(29) Fosdick, S. E.; Crooks, R. M., Bipolar electrodes for rapid screening of electrocatalysts. J. Am. Chem. Soc. 2012, 134, 863-866.

(30) Chow, K.-F.; Mavré, F.; Crooks, J. A.; Chang, B.-Y.; Crooks, R. M., A large-scale wireless electrochemical bipolar electrode microarray. $J$. Am. Chem. Soc. 2009, 131, 8364-8365.

(31) Chow, K.-F.; Mavré, F.; Crooks, R. M. Wireless electrochemical DNA microarray sensor. J. Am. Chem. Soc. 2008, 130, 7544-7545.

(32) de Poulpiquet, A.; Diez-Buitrago, B.; Milutinovic, M.; Goudeau, B.; Bouffier, L.; Arbault, S.; Kuhn, A.; Sojic, N., Dual-color electrogenerated chemiluminescence from dispersions of conductive microbeads addressed by bipolar electrochemistry. ChemElectroChem 2016, 3, 404-409.

(33) de Poulpiquet, A.; Diez-Buitrago, B.; Dumont Milutinovic, M.; Sentic, M.; Arbault, S.; Bouffier, L.; Kuhn, A.; Sojic, N., Dual enzymatic detection by bulk electrogenerated chemiluminescence. Anal. Chem. 2016, 88, 6585-6592.

(34) Sentic, M.; Arbault, S.; Goudeau, B.; Manojlovic, D.; Kuhn, A.; Bouffier, L.; Sojic, N., Electrochemiluminescent swimmers for dynamic enzymatic sensing. Chem. Comm. 2014, 50, 10202-10205.

(35) Bouffier, L.; Doneux, T.; Goudeau, B.; Kuhn, A., Imaging redox activity at bipolar electrodes by indirect fluorescence modulation. Anal. Chem. 2014, 86, 3708-3711.

(36) Zhang, X.; Zhai, Q.; Xing, H.; Li, J.; Wang, E., Bipolar electrodes with $100 \%$ Current efficiency for sensors. ACS Sensors 2017, 2, 320-326.

(37) Eßmann, V.; Jambrec, D.; Kuhn, A.; Schuhmann, W., Linking glucose oxidation to luminol-based electrochemiluminescence using bipolar electrochemistry. Electrochem. Commun. 2015, 50, 77-80.

(38) Qi, W.; Lai, J.; Gao, W.; Li, S.; Hanif, S.; Xu, G., Wireless electrochemiluminescence with disposable minidevice. Anal. Chem. 2014, 86, 8927-8931.

(39) Zhang, J.-D.; Yu, T.; Li, J.-Y.; Xu, J.-J.; Chen, H.-Y., An ITO bipolar array for electrochemiluminescence imaging of $\mathrm{H}_{2} \mathrm{O}_{2}$. Electrochem. Commun. 2014, 49, 75-78.

(40) Wang, T.; Fan, S.; Erdmann, R.; Shannon, C., Detection of ferrocenemethanol and molecular oxygen based on electrogenerated chemiluminescence quenching at a bipolar electrode. Langmuir 2013, 29, 16040-16044.

(41) Wu, M.-S.; Yuan, D.-J.; Xu, J.-J.; Chen, H.-Y., Electrochemiluminescence on bipolar electrodes for visual bioanalysis. Chem. Sci. 2013, 4, 1182-1188.

(42) Wu, S.; Zhou, Z.; Xu, L.; Su, B.; Fang, Q., Integrating bipolar electrochemistry and electrochemiluminescence imaging with microdroplets for chemical analysis. Biosens. Bioelectron. 2014, 53, 148153.

(43) Guerrette, J. P.; Percival, S. J.; Zhang, B., Fluorescence coupling for direct imaging of electrocatalytic heterogeneity. J. Am. Chem. Soc. 2013, 135, 855-861

(44) Bryan, A. M.; Santino, L. M.; Lu, Y.; Acharya, S.; D’Arcy, J. M., Conducting polymers for pseudocapacitive energy storage. Chem. Mater. 2016, 28, 5989-5998.

(45) Orozco, J.; Cortés, A.; Cheng, G.; Sattayasamitsathit, S.; Gao, W. Feng, X.; Shen, Y.; Wang, J., Molecularly imprinted polymer-based catalytic micromotors for selective protein transport. J. Am. Chem. Soc. 2013, 135, 5336-5339.

(46) Ding, M.; He, Q.; Wang, G.; Cheng, H.-C.; Huang, Y.; Duan, X., An on-chip electrical transport spectroscopy approach for in situ monitoring electrochemical interfaces. Nat. Commun. 2015, 6, 7867.

(47) Katz, E.; Willner, I., A Biofuel Cell with Electrochemically Switchable and Tunable Power Output. J. Am. Chem. Soc. 2003, 125, 6803-6813.

(48) Wang, J., Electrochemical glucose biosensors. Chem. Rev. 2008 , $108,814-825$.

(49) Zayats, M.; Katz, E.; Willner, I., Electrical contacting of flavoenzymes and $\mathrm{NAD}(\mathrm{P})+$-dependent enzymes by reconstitution and affinity interactions on phenylboronic acid monolayers associated with Au-electrodes. J. Am. Chem. Soc. 2002, 124, 14724-14735.

(50) Etienne, M.; Zhang, L.; Vilà, N.; Walcarius, A., Mesoporous materials-based electrochemical enzymatic biosensors. Electroanalysis 2015, 27, 2028-2054.

(51) Khan, G. F.; Ohwa, M.; Wernet, W., Design of a stable charge transfer complex electrode for a third-generation amperometric glucose sensor. Anal. Chem. 1996, 68, 2939-2945. 
(52) Calvo-Marzal, P.; Chumbimuni-Torres, K. Y.; Höehr, N. F.; de Oliveira Neto, G.; Kubota, L. T., Determination of reduced glutathione using an amperometric carbon paste electrode chemically modified with TTF-TCNQ. Sens. Actuators B: Chem. 2004, 100, 333-340.

(53) Zhan, W.; Alvarez, J.; Crooks, R. M., Electrochemical sensing in microfluidic systems using electrogenerated chemiluminescence as a photonic reporter of redox reactions. J. Am. Chem. Soc. 2002, 124, 1326513270.

(54) Swoboda, B. E. P.; Massey, V., Purification and properties of the glucose oxidase from aspergillus niger. J. Bio. Chem. 1965, 240, 22092215.

(55) Gibson, Q. H.; Swoboda, B. E. P.; Massey, V., Kinetics and mechanism of action of glucose oxidase. J. Bio. Chem. 1964, 239, 3927-3934.

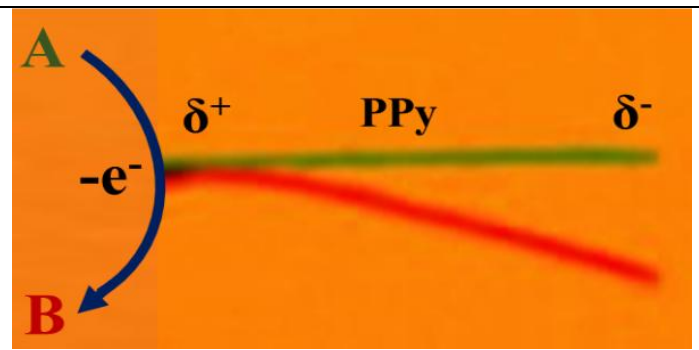

